\title{
Encouraging compassion through teaching and learning: a case study in Cyprus
}

\author{
Sue Shea ${ }^{1,2^{*}}$, George Samoutis ${ }^{3}$, Robin Wynyard ${ }^{4}$, Andreas Samoutis ${ }^{5}$, Christos Lionis ${ }^{2}$, Andreas Anastasiou ${ }^{6}$, \\ Alice Araujo ${ }^{7}$, Alexia Papageorgiou ${ }^{3}$ and Renos Papadopoulos ${ }^{8}$
}

\begin{abstract}
Background: It has been suggested that the biomedical approach towards healthcare professional training may neglect the humanistic nature and personal values of care. As such, discussions with regard to the importance of introducing compassion training into undergraduate programmes and throughout professional practice are of interest. Within this paper, we report on a compassionate care programme designed for, and delivered to, healthcare professionals and managerial/administrative staff at a private hospital in Limassol, Cyprus.
\end{abstract}

Case description: Six modules were developed, each of a $6 \mathrm{~h}$ duration. Each module was delivered twice to two separate groups of participants. Participants included 60 healthcare professionals along with 5 managerial and administrative staff. Using a range of innovative teaching methods and activities, the programme covered a number of issues relevant to compassion including patient centred care, therapeutic relationships, empathy, cultural awareness, conflict resolution, and advanced communication skills. The programme was evaluated using both qualitative and quantitative methods.

Discussion: Quantitative and qualitative feedback demonstrated high satisfaction and interest in the programme. Likewise, attending managerial and administrative staff considered the programme important for quality improvement and organizational culture change.

Our findings demonstrate that programmes covering the topic of compassion are welcomed by both healthcare professionals and managerial/administrative staff. The impact of compassionate care training will be assessed effectively through a future longitudinal study.

Keywords: Compassion, Education, Teaching methods, Organizational culture

\section{Background}

Interest in the topic of compassion, often defined as 'sensitivity to the pain or suffering of another, coupled with a deep desire to alleviate that suffering' [1], has escalated in recent years attracting much discussion and work at a multidisciplinary level to integrate the concept $[2,3]$. Concerns that healthcare sometimes fails at a fundamental level have received much attention globally, particularly following the release of the Francis Report which was based on an enquiry into devastating events concerning care of patients at Mid-Staffordshire Hospital in the UK [4].

Evidence suggests that a compassionate approach could facilitate a faster recovery from acute illness, better

\footnotetext{
* Correspondence: sueshea1@otenet.gr

${ }^{1}$ Research Centre for Transcultural Studies in Health, Middlesex University, London, UK

${ }^{2}$ Clinic of Social and Family Medicine, University of Crete, Crete, Greece

Full list of author information is available at the end of the article
}

management of chronic illness, and improvement of psychological symptoms such as anxiety and depression. Studies have also shown that kindness and touch alter the heart rhythm and brain function - both for the person providing compassion and the person receiving it [5-7]. Furthermore, a compassionate approach is believed to alter the brain's response to stress and assist in increasing pain tolerance [2].

According to Chrousos [8], expression of compassion represents an interaction between two emotionally resonating stressed persons: the caring and the cared. In addition, Cole-King and Gilbert [9] draw attention to the fact that the scientific understanding of such relationships and their profound physiological effects ought to make compassionate care a more central concern in medical and nursing training and practice. It is often considered that the biomedical approach of nurse/medical training may lead to 
a decrease in compassion. Haslam [10] reports that research has shown that some medical students may lose the ability to empathise with their patients during clinical training. Indeed as early as 1961, Howard Becker suggested that values in healthcare may be 'taught out' of medical students during their training [11], whilst Newton et al. [12], referred to the 'hardening of the heart' during medical school. This issue is believed to be common in many countries, whereby an emphasis on promoting biomedical knowledge in doctors and nurses may over-ride a focus on clinical reasoning, practical skills, and development of character and compassion [13].

Compassion is a virtue that can be potentially strengthened and cultivated through training. Indeed the Francis Report, advocates training in compassionate care, and recommends that aptitude tests for compassion should be introduced [4].

It would seem logical that whilst compassion may be viewed by some as an innate quality, efforts to sustain and encourage the concept should be included within undergraduate training, and should also form an ongoing part of professional development for trained practitioners. Saunders [14] suggests that although our dispositions vary, compassion is a quality that can be developed in all of us. However, compassion extends further than the relationship between patient and practitioner, and should also be encouraged across the healthcare team and should include all of those involved in the healthcare setting. Factors such as time pressure, lack of teamwork and communication, and structure of the organisation in general, may all lead to a decrease in compassion. Thus, if we are to develop a compassionate organization, training programmes should be developed to include not only doctors, nurses, and allied health professionals, but also managerial/administrative staff and policy makers.

\section{Can compassion be taught?}

'educating the mind without educating the heart is no education at all'

\section{(Aristotle - from Nicomachean Ethics (Book II, Chapter 9, Paragraph 1)}

A key question that is often asked, is can compassion be taught? Following a symposium held at Greenwich University in 2011 [15], participants were invited to address this question, which led to a discussion on various aspects in relation to teaching and assessing compassion, such as the process of life-long learning and the need to encourage suitable role models. The process of learning was considered just as important as the method of teaching.

Debate as to whether or not compassion can be taught has existed for some time, and as far back as 1983, Pence
[16] raised this question in a well-cited essay, utilizing the differing views of ancient philosophers with regard to general virtues. Pence drew on the opinions of Socrates (who claimed that virtues cannot be taught), and Protagoras (who claimed that everyone teaches virtues), concluding that compassion can be taught if medical education systems reward this virtue alongside other medical virtues, thus ensuring its sustainability.

In a systematic review by Lee et al. [17] compassion was considered as a subjective emotion which is challenging to define. These authors concluded that educators need innovative ways to evoke emotions in healthcare professionals to enhance compassionate care. Improving communication skills, self-compassion, and self-reflection could help to determine this.

Many feel that the integration and utilisation of the arts and humanities can be useful for enhancing compassion. Chochinov [18] reports that compassion can be arrived at through various channels, and may be cultivated by exposure to the humanities, social sciences and arts. Such a multidisciplinary approach can help to offer an insight into the human condition and the pathos that accompanies illness. Likewise, Haslam [10], suggests that indeed empathy is a trainable quality if we cultivate the habit of self-reflection, and learn from humanities such as literature, film, theatre, and poetry which will help us imagine the lives of others.' Egan [19] additionally suggests that an important quality that helpers need to develop is relationship flexibility, the ability to adjust their communication styles in order to strengthen the therapeutic relationship with each patient while remaining true to themselves. This notion of genuineness is at the crux of many theories, particularly Carl Roger's [20] person-centered phenomenological approach. Rogers believes that the meaningful therapeutic relationship is developed and maintained when the helper communicates to the patient unconditional positive regard, empathy, and genuineness.

There are various indications that compassion can be taught, or that it can at least be brought to the forefront and encouraged in both medical/nursing students and practising healthcare professionals. Initiatives in this area are ongoing, and one such example is a course that has been developed on the island of Crete, Greece, for delivery to first year medical students [21]. This course attracts great interest from students, with many of them reporting that it improves their understanding of compassion. A further example is that of the Leadership in Compassionate Care Programme (LCCP) offered at Edinburgh Napier University and NHS Lothian in Scotland. The LCCP aims to 'embed compassionate nursing within clinical practice and pre-registration nursing education' and has received very positive feedback from student nurses [22]. 
If compassion is to be encouraged and sustained, then it could perhaps be helpful to initiate courses not only within undergraduate training, but also for ongoing professional development to utilise the concept by way of courses, reflective learning, and learning from 'what goes right' in practice as well as 'what goes wrong' [23].

Given the above, and the perceived importance of investigating whether compassion can be taught, within the remainder of this paper we report on a compassion training programme that was developed with the purpose of involving not only clinical staff, but administration and managerial staff as well. The course was delivered in 2015 to staff at Ygeia Hospital in Limassol, Cyprus.

\section{Case presentation: 'Cultivating compassion in hospitals - improving quality of care' Limassol, Cyprus 2015}

The impetus for the above programme resulted from discussions initiated in Cyprus concerning the potential need and usefulness of enhancing and encouraging nonclinical aspects of care such as patient-centredness, the therapeutic relationship, advanced communication skills, empathy, and other elements relevant to the delivery of compassionate healthcare. Following discussions with management staff and relevant healthcare professional leads at a private hospital in Limassol, Cyprus, a tailored training programme was developed with the intention of providing a practical framework for developing compassion for one's self and others.

The aims and expected benefits for programme participants included the following: increased ability to handle stressful work situations; more meaningful connections with patients and co-workers; better ability to engage and collaborate with team members; greater job satisfaction, reduced compassion fatigue, and an overall increase in productivity and quality of care.

The resulting educational course was expected to improve the quality of care through improvement of the culture of the organization, patient contacts (administrative staff, healthcare professionals etc.), improved patient satisfaction, reduced medical errors and liability risks, and improved collaboration and communication resulting in enhanced efficiency and productivity. The intention was to achieve these goals through enhancing and deepening the qualities of compassion, empathy, kindness, self awareness, self-reflection, conflict resolution, mindful and effective communication, and compassionate care skills. An increasing body of evidence clearly suggests the causal relationship between compassion and quality of care. For example, Del Canale et al. (2012) [24] report that physician empathy is significantly associated with clinical outcome for patients with diabetes mellitus and should be considered an important component of clinical competence. Moreover, a systematic review and meta-analysis of RCTs suggest that the patient-clinician relationship has a small, but statistically significant effect on healthcare outcomes [25].

A unique feature of the programme rested in its intended function as a vehicle for bringing both practicing healthcare professionals and managerial/administrative staff together in unison to reflect on and discuss the importance of a compassionate approach across the healthcare setting, as well as to improve the culture of the organization. Participants were challenged to reflect on their own capacity for compassion and empathy and to discuss how interpersonal and organizational factors could help develop and enhance, or instead compromise, the quality and effectiveness of various work setting relationships.

\section{Programme delivery}

The programme was delivered at Ygeia hospital in Cyprus. Ygeia Hospital is a general hospital with 27 specialties and a capacity of 152 beds. The hospital employs more than 200 associate physicians and 473 medical, nursing and administrative staff, thus making it one of the largest employers in Cyprus.

The programme was offered to nurses, doctors, and administrative staff employed by the hospital. Participants consisted of mainly nurses, although 8 doctors and 5 managerial/administrative staff also attended. All participants were offered CPD credits.

The vast majority of the participants were selected by the medical and nursing management team as part of their continuing professional development. The selected participants were able to take time away from work to attend the course.

Demographic information relating to the participating HCPs can be seen in Table 1 .

The programme consisted of six modules delivered over a period of 6 months. Each module was delivered twice to two separate groups of participants. The design of the modules was based on the outcome of focus group meetings with the hospital Board of Directors, Human Resources staff, and healthcare professionals, in terms of their needs, ideas, and expectations. The modules were cumulative so that each session would build on the previous ones.

At the beginning of the first module, participants were each given a randomly distributed colour-coded card, and

\begin{tabular}{ll} 
Table 1 Demographic details of participating HCPs \\
$\begin{array}{ll}\text { Gale }=20(33.3 \%) \\
\text { Fender } \\
\text { Age }\end{array}$ \\
$\begin{array}{l}\mathrm{m}=30 \text { (66.7 } \%) \\
\text { Years of Service }\end{array}$ \\
$\begin{array}{l}\text { Nurse participants } \\
\text { Physician participants }\end{array}$ & $\mathrm{N}=52.6$ years (minimum 0.5, maximum 20) \\
$\begin{array}{l}\text { Administrative staff } \\
\text { participants }\end{array}$ & $\mathrm{N}=8$ \\
\hline
\end{tabular}


were then asked to join other members of the group who held the same colour card. This initiative was intended to encourage meeting new people and working with colleagues other than those encountered on a usual daily basis.

A number of innovative teaching methods were utilized, in order to engage the participants and encourage interactive learning. Teaching methods included the use of presentations, theory-based discussion, videos, role play, stories, real-life examples, and a range of other activities. The teaching methodology was based on a combination of didactic, practical and experiential modes of learning. The first refers to theoretical tuition in seminar form, the second to practice of set skills through role playing, and the third refers to exposure to planned settings that experientially are comparable to actual application situations. The modules covered a range of relevant issues including: applying compassion in the healthcare setting; patient-centred care; conflict transformation; intercultural communication; advanced communication skills; and the therapeutic compassionate relationship.

The training methods that we used were based on Kolb's experiential learning cycle, which is described as a progression through 4 stages, these being experience, reflection, conceptualization to action and further experience [26] Moreover, we stressed that participants pursue meaningful change with reflections on experiences or actions [27]. Futhermore, a case based approach was also used during the trainings [28].

Table 2 provides an overview of the module descriptions.

The programme was delivered by a multidisciplinary team including HCPs, psychologists, sociologists, and an Associate Professor in clinical communication who was responsible for the clinical communication component of the course.
In addition, a further unique feature was the involvement of the programme leader's son who assisted in the organization and delivery of various activities.

The modules were presented mainly in the Greek language, except in cases where the presenter's native language was English. In such cases, translation was provided (where necessary) by the programme leader and his young son - both of whom are fluent in English as well as Greek or, in one case, by one of the other presenters.

Finally, the success of each module was evaluated by participants at the end of the session, using both qualitative and quantitative methods.

\section{Evaluation}

Each individual module was evaluated both quantitatively and qualitatively by the use of a questionnaire which was distributed to the participants by the course teachers. Participants completed the evaluation questionnaire at the end of each module. The responses to each module were then merged to provide an evaluation for the programme overall. The quantitative evaluations demonstrated that the programme had been successful, with a large percentage of participants responding with either 'very good' or 'excellent' to the 11 questions asked on the evaluation form. The evaluation items and percentages can be seen on Table 3 .

Responses to the qualitative question were also very positive, and example responses can be seen in Table 4 .

With regard to the participating managerial/administrative staff, follow-up discussions with them elicited the following responses:

'A great experience that gave us the chance to touch upon sensitive and burning issues i.e. relationships and

Table 2 Module descriptions

\begin{tabular}{|c|c|}
\hline Module title & Content \\
\hline $\begin{array}{l}\text { 1. Applying Compassion within the context of the } \\
\text { hospital setting }\end{array}$ & $\begin{array}{l}\text { Historical and religious backgrounds; attention to basic needs; example approaches } \\
\text { to specific conditions; compassion across the organisation; cultural awareness; } \\
\text { compassionate care during financial crisis; barriers and sustainability; can compassion } \\
\text { be taught }\end{array}$ \\
\hline 2. Patient centred care in hospitals & $\begin{array}{l}\text { Main concepts and measurements; how to apply, what we need to change } \\
\text { among the health care workforce, organizations and patients; seeing the } \\
\text { person in the patient; implementation in the local setting - barriers and constraints }\end{array}$ \\
\hline 3. Applied compassionate care & $\begin{array}{l}\text { Developing a culture of compassionate care; enabling compassionate care } \\
\text { in acute hospital settings; applied compassionate care; conflict transformation }\end{array}$ \\
\hline $\begin{array}{l}\text { 4. Intercultural Communication Competence in } \\
\text { Healthcare; Teamwork Communication in Healthcare }\end{array}$ & $\begin{array}{l}\text { The impact of culture in doctor-patient relationships as well as among staff } \\
\text { members in healthcare settings; communication dynamics and strategies for } \\
\text { effective and compassionate self-care, patient care, and in healthcare work teams. }\end{array}$ \\
\hline 5. Advanced communication skills & $\begin{array}{l}\text { Impact of consultation and communication style on the patient's experience; } \\
\text { advanced communication skills; employing effective communication tools; } \\
\text { assessment of improvement of communication and consultation skills }\end{array}$ \\
\hline 6. The therapeutic compassionate relationship & $\begin{array}{l}\text { The healthcare Professional as a drug; impact of a good quality therapeutic } \\
\text { relationship in patient satisfaction, professional fulfillment, compliance, } \\
\text { complaints and effective time management; measuring the therapeutic relationship }\end{array}$ \\
\hline
\end{tabular}


Table 3 Quantitative responses

\begin{tabular}{llll}
\hline Question & $\begin{array}{l}\text { \% Excellent/N. Good } \\
\text { Both Groups }\end{array}$ & $\begin{array}{l}\text { \% Excellent/V. Good } \\
\text { Group A }\end{array}$ & $\begin{array}{l}\text { \% Excellent/N. Good } \\
\text { Group B }\end{array}$ \\
\hline 1. Does he/she present material in a well organized fashion? & $92 \%$ & $95 \%$ & $89 \%$ \\
2. Does he/she use enough examples or illustrations to clarify the material? & $91 \%$ & $95 \%$ & $85 \%$ \\
3. Is he/she helpful when the participants have difficulty? & $88 \%$ & $91 \%$ & $82 \%$ \\
4. Is he/she enthusiastic about the subject taught? & $82 \%$ & $95 \%$ & $86 \%$ \\
5. Does he/she make students feel free to participate? & $89 \%$ & $96 \%$ & $85 \%$ \\
6. Does he/she make the subject interesting? & $90 \%$ & $91 \%$ & $88 \%$ \\
7. Does he/she treat all students equally? & $87 \%$ & $90 \%$ & $83 \%$ \\
8. Does he/she explain material clearly? & $91 \%$ & $83 \%$ & $88 \%$ \\
9. Does he/she seem to know his/her subject? & $88 \%$ & $88 \%$ \\
10. Does he/she manage the class well? & $86 \%$ & \\
11. Considering all the above qualities, how would you rate the module overall? & $86 \%$ & \\
\hline
\end{tabular}

collaboration between HCPs, cultural awareness, communication skills, empathy etc'.

\section{'Excellent motivator for our HCPs to deliver patient centred care'}

'Experiential learning that will facilitate our efforts for quality improvement and organizational culture changes'.

\section{Discussion}

The programme described in this paper provided us with a valuable opportunity to deliver in-depth structured teaching in order to enhance non-clinical aspects of care and to identify the needs of our participants. Although the programme was somewhat experimental, in that this was the first time it had been delivered, the organization of it allowed for flexibility and adaptation throughout in terms of the content and selecting which material was appropriate for our target audience. Positive feedback

Table 4 Examples of quantitative responses

\begin{tabular}{l}
\hline Participants were invited to respond to the following question: \\
'Please share with us your views regarding the subjects of the course, \\
and the teaching methodology - were these successful, and could they \\
be improved?' \\
Excellent \\
Inspiring \\
This module was perfect all the time and very helpful \\
The explaining and trainings has been very clear \\
Delighted to have both languages as this made it so much more \\
interesting, understandable by all, thank you and well done \\
The positive atmosphere \\
Very interesting \\
All excellent \\
It was very interesting, thank you \\
A very pleasant presentation of the subject \\
It improves the way that I communicate \\
A most comprehensive approach to humans particularly the patient \\
\hline
\end{tabular}

was received from both the participating $\mathrm{HCPs}$ and managerial/administrative staff.

On the basis of our experience with regards to the above mentioned course, and the success of other compassion based courses, we suggest that the introduction of courses on compassionate care within medical and nurse training is both feasible and can greatly support quality improvement strategies of the local organizations. Thus, we advocate and encourage discussion on the importance of training and encouraging the importance of a compassionate approach.

Many undergraduate health care degrees, have now adopted compassionate care teaching especially in medical education which is also recommended by the General Medical Council (GMC) [29]. Ideally, such courses could be delivered as part of undergraduate training in all healthcare programmes and could feature as part of continuous professional development across the entire healthcare setting. The course reported here is expected to improve the quality of care through improvement of the culture of the organization, and the impact of compassionate care training programmes on quality improvement will be assessed effectively through a future longitudinal study.

Following the success and the feedback that was received from the management, healthcare professionals, and tutors of the Cyprus course, the organizers have established the non for profit "International Institute for Compassionate Care". The purpose of the institute is to bring together individuals, non for profit initiatives, patient organizations and academic institutions from all over the world and synergistically foster collaboration, research, and networking, together with the provision of face to face and on-line state of the art training courses.

\section{Young people and compassion}

Having the involvement of the programme director's 15 year old son, brought our attention to the importance 
of cultivating the concept in young people as well as in adults, and this is an issue that the authors would like to further develop and encourage.

According to a blog by Whitson in the Huffington Post [30], experts agree that fostering compassion in young people is among the best ways to prevent verbal, physical, and emotional aggression from taking root. Likewise in a recent study wherein investigators trained young adults to engage in compassion meditation, remarkable alterations in brain function were observed, compared to a control group [31]. These researchers conclude that compassion, like physical and academic skills, appears to be something that is not fixed, but rather can be enhanced with training and practice.

It would appear that the cultivation and encouragement of compassion in young people should also represent an important focus. As such, we would like to draw attention to the importance of cultivating compassion in young people as well as adults, and encouraging their participation in activities such as the training programme outlined here.

\section{Recommendations}

An important feature of the course lies in the involvement of managerial and administrative staff in addition to a range of HCPs from different clinical backgrounds within the hospital. Managerial staff welcomed the opportunity to participate, which is of paramount importance in terms of facilitating organizational cultural changes. An additional strength was the flexibility of the programme in that it allowed for the course material to be adapted to suit the target audience.

However, certain limitations were observed. Of the participating $\mathrm{HCPs}$, most of them were nursing staff, and the hospital management has since indicated that they would like to encourage more doctors to participate in future courses. Another potential limitation is that some participants felt that at $6 \mathrm{~h}$ per session, the programme was rather long. Members of the first group of participants attended the workshop at the conclusion of their 7-h early morning to afternoon work shifts, which could have potentially compromised their ability to focus on the content, meaningfully participate in discussion, and/or to retain information. The programme team will address these issues by making the necessary adjustments when planning future courses. In general it is felt that the delivery of a blended programme (face to face and e-learning teaching methodology) would be desirable. In addition, a number of measurements (e.g. confidence in ability to communicate and empathise) could be used to assess the participants' compassion before and after they receive the training. A further limitation was that on this occasion it was not possible to conduct a follow up evaluation of the programme, but the programme team will ensure that future courses are evaluated 6 months after the programme as well as at the time of the programme delivery.

Involvement in this training programme was a useful learning experience for all of us. We realised the importance of including administrative and managerial staff in the programme, and learned that this was very much welcomed. In future programmes we aim to address certain issues such as the encouragement of moredoctors onto the programme, and shortening the length of the programme.

\section{Conclusions}

In conclusion, it appears that compassion and compassionreflective behaviors can be taught or enhanced in sustainable ways through continuing education in short course format or through inclusion in the medical/nursing curricula. Such education should extend to all involved in the healthcare team. Ongoing training, reflective learning, learning by experience, role-modelling, blended teaching or other innovative teaching methods and long-term evaluation may all help to sustain the virtue of compassion in the longer term thus continuously improving the quality of care. Programmes such as the training outlined here can have a wide impact in healthcare by exposing participants to the important humanistic values in healthcare. The impact of compassionate care training will be assessed effectively through a future longitudinal study.

\section{Acknowledgments}

Not applicable.

Funding

Not applicable.

Availability of data and material Not applicable.

\section{Authors' contributions}

SS contributed to the design and delivery of the programme and prepared the main text of the manuscript. GS conceived and directed the idea for the programme, contributed to the design and delivery, and assisted in the revision of the manuscript. RW contributed to the design and delivery of the programme and assisted in the revision of the manuscript. AS contributed to the design and delivery of the programme and assisted in the revision of the manuscript. CL contributed to the design and delivery of the programme and assisted in the revision of the manuscript. An.A contributed to the design and delivery of the programme and assisted in the revision of the manuscript. Al.A contributed to the design and delivery of the programme and assisted in the revision of the manuscript. AP contributed to the design and delivery of the programme and assisted in the revision of the manuscript. RP contributed to the design and delivery of the programme and assisted in the revision of the manuscript. All authors read and approved the final manuscript.

\section{Competing interests}

The authors declare they have no competing interests.

Consent for publication

Not applicable.

Ethics approval and consent to participate Not applicable. 


\section{Author details}

'Research Centre for Transcultural Studies in Health, Middlesex University, London, UK ${ }^{2}$ Clinic of Social and Family Medicine, University of Crete, Crete, Greece. ${ }^{3}$ University of Nicosia Medical School, Nicosia, Cyprus. ${ }^{4}$ Sociologist, Whitstable, Kent, UK ${ }^{5}$ GC School of Careers, London, UK. ${ }^{6}$ University of Nicosia, Nicosia, Cyprus. ${ }^{7}$ Apostolos Loukas Medical Centre, Engomi, Nicosia, Cyprus. ${ }^{8}$ Centre for Trauma, Asylum and Refugees, University of Essex, London, UK

\section{Received: 15 February 2016 Accepted: 1 October 2016}

\section{Published online: 22 October 2016}

\section{References}

1. Goetz JL, Keltner D, Simon-Thomas E. Compassion: an evolutionary analysis and empirical review. Psychol Bull. 2010;136(3):351-74.

2. Youngson R. Time to care: how to love your patients and your job. New Zealand: Rebelheart Publishers; 2012

3. Shea S, Wynyard R, Lionis C, editors. Providing compassionate healthcare: challenges in policy and practice. Oxon and New York: Routledge; 2014.

4. Francis R QC. Report of the mid staffordshire NHS foundation trust public inquiry. House of Commons: Stationary Office 2013, Vols 1-3

5. Fogarty LA, Curbow BA, Wingard JR, McDonnell K, Summerfield MR. Can 40 seconds of compassion reduce patient anxiety? J Clin Oncol. 1999:17(1):371.

6. Shaltout HA, Toozer JA, Rosenberger MA, Kemper KJ. Time, touch, and compassion: effects on autonomic nervous system and well-being. Explore. 2012;8(3):177-84.

7. Science Daily website. http://www.sciencedaily.com. Accessed Jan 2015

8. Chrousos GP. Empathy, stress and compassion: resonance between the caring and the cared. In: Shea S, Wynyard R, Lionis C, editors. Providing compassionate healthcare: challenges in policy and practice. London: Routledge; 2014

9. Cole-King A, Gilbert P. Compassionate care: the theory and the reality. In: Shea S, Wynyard R, Lionis C, editors. Providing compassionate healthcare: challenges in policy and practice. London: Routledge; 2014.

10. Haslam D. "More than kindness" Journal of Compassionate Health Care 2015;2(6) (online)

11. Becker H, Geer B, Hughes EC, Strauss AL. Boys in white: student culture in medical school. USA and London: Transaction Publishers; 1961.

12. Newton B, Barber L, Clardy J, Cleveland E, O'Sullivan P. Is there hardening of the heart during medical school? Acad Med. 2008;83(3):244-9.

13. Danielsen RD, Cawley JF. Compassion and integrity in health professions education. The Internet Journal of Allied Health Sciences and Practice. 2007:5(2):1-9.

14. Saunders J. Compassion. Clin Med. 2015;15(2):121-4

15. Shea $S$, Wynyard $R$, West $E$, Lionis $C$. Reaching a consensus in defining and moving forward with the science and art of compassion in healthcare. Journal of Holistic Health Care. 2011;8:58-60.

16. Pence GE. Can compassion be taught? J Med Ethics. 1983:9:189-91.

17. Lee M, Laurenson M, Whitfield C. Can compassion be taught to lessen the effects of compassion fatigue? Journal of Care Services Management. 2012;6(3):121-30

18. Chochinov HM. Dignity and the essence of medicine: the $A, B, C$, and D of dignity conserving care. BMJ. 2007;335:184

19. Egan G. The skilled helper: a problem-management and opportunitydevelopment approach to helping/edition 10. 2013.

20. Rogers C. A way of being. Boston: Houghton Mifflin; 1980.

21. Lionis C, Shea S, Markaki A. Introducing and implementing a compassionate care effective for medical students in Crete. Journal of Holistic Healthcare. 2011:8:38-41.

22. Adamson L, Smith S. Can compassion be taught/experiences from the leadership in compassionate care programme, Edinburgh Napier University and NHS Lothian. In: Shea S, Wynyard R, Lionis C, editors. Providing compassionate health care challenges in policy and practice. Oxon and New York: Routledge; 2014.

23. Lionis C, Shea S. Compassion in medicine or medicine with compassion? Eurodigest. 2015;2(1):9-12.

24. Del Canale S, Louis DZ, Maio V, Wang X, Rossi G, Hojat M, et al. The relationship between physician empathy and disease complications: an empirical study of primary care physicians and their diabetic patients in Parma, Italy. Acad Med. 2012;87(9):1243-9.

25. Kelley JM, Kraft-Todd G, Schapira L, Kossowsky J, Riess H. The influence of the patient-clinician relationship on healthcare outcomes: a systematic review and meta-analysis of randomized controlled trials. PLoS One. 2014;9(4):e94207.
26. Kolb DA. Experiential learning: experience as the source of learning and development. Englewood Cliffs: Prentice Hall; 1984.

27. Schon D. The reflective practitioner: how professionals think in action. New York: Basic Books; 1990

28. Hays R. A practical guide to curriculum design: problem-based, case-based or traditional? Clin Teach. 2008;5:73-5.

29. General Medical Council (GMC) (http://www.gmc-uk.org/guidance/25070. asp) Accessed Jan 2015

30. Whitson, S. 8 ways to teach compassion to kids (http://www.huffingtonpost com/signe-whitson/8-ways-to-teach-compassio_b_5568451.html) Accessed Jan 2015

31. Brain can be trained in compassion, study shows. (http://www. psychologicalscience.org/index.php/news/releases/compassion-training. html) Accessed Jan 2015

\section{Submit your next manuscript to BioMed Central and we will help you at every step:}

- We accept pre-submission inquiries

- Our selector tool helps you to find the most relevant journal

- We provide round the clock customer support

- Convenient online submission

- Thorough peer review

- Inclusion in PubMed and all major indexing services

- Maximum visibility for your research

Submit your manuscript at www.biomedcentral.com/submit
Biomed Central 